\title{
Low doses of the novel caspase-inhibitor GS-9450 leads to lower caspase-3 and -8 expression on peripheral CD4+ and CD8+ T-cells
}

\author{
J. E. Arends • A. I. M. Hoepelman • \\ N. M. Nanlohy $\cdot$ F. J. P. Höppener • \\ K. R. Hirsch · J. G. Park • D. van Baarle
}

Published online: 11 June 2011

(c) The Author(s) 2011. This article is published with open access at Springerlink.com

\begin{abstract}
Chronic hepatitis C virus (HCV) infection is characterized by increased rates of apoptotic hepatocytes and activated caspases have been shown in HCV-infected patients. GS-9450, a novel caspase-inhibitor has demonstrated hepatoprotective activity in fibrosis/apoptosis animal models. This study evaluated the effects of GS9450 on peripheral T-cell apoptosis in chronic HCVinfected patients. As sub study of the GS-US-227-0102, a
\end{abstract}

Part of this work was presented as poster (862) at the 61th Annual Meeting of the American Association for Studying the Liver (AASLD), October 30th-November 2nd 2010, Boston, United States of America.

For future correspondence to K.R. Hirsch, contact Mr. Steven Knox, Gilead Sciences, Inc., Foster City, CA, USA.

J. E. Arends $(\bowtie)$ - A. I. M. Hoepelman · D. van Baarle Department of Internal Medicine and Infectious Diseases, University Medical Center Utrecht (UMCU), F02.126,

Heidelberglaan 100, P.O. Box 85500, 3508, GA, Utrecht,

The Netherlands

e-mail: j.e.arends@umcutrecht.nl

J. E. Arends · N. M. Nanlohy · D. van Baarle

Department of Immunology, University Medical Center Utrecht

(UMCU), F02.126, Heidelberglaan 100, P.O. Box 85500, 3508,

GA, Utrecht, The Netherlands

F. J. P. Höppener

Clinical Pharmacology Unit, Kendle International B.V.,

Utrecht, The Netherlands

K. R. Hirsch

Gilead Sciences, Inc., Durham, NC, USA

J. G. Park

LG Life Sciences, Ltd., Seoul, Korea double-blind, placebo-controlled phase 2 a trial evaluating the safety and tolerability of GS-9450, apoptosis of peripheral $\mathrm{CD} 4+$ and $\mathrm{CD} 8+\mathrm{T}$-cells was measured using activated caspase-3, activated caspase-8 and CD95 (Fas). Blood samples were drawn at baseline, day 14 after therapy and at 5 weeks off-treatment follow-up in the first cohort of $10 \mathrm{mg}$. In contrast to the placebo-treated patients, GS-9450 caused a median of $46 \%$ decrease in ALT-values from baseline to day 14 in all treated patients (median of 118-64 U/l) rising again to a median of $140 \mathrm{U} / 1(19 \%)$ at 5 weeks off-treatment follow-up. In GS9450-treated patients, during treatment and follow-up, percentages of activated caspase- $3+$ and caspase- 8 expression tended to decrease, in contrast to placebo-treated patients. Interestingly, compared to healthy controls, higher percentages of caspase- 3 and caspase- 8 positive CD4+ and CD8+ T-cells were demonstrated in $\mathrm{HCV}$-infected patients at baseline. Decreased ALT-values were observed in all HCV-infected patients during treatment with low dose of the caspaseinhibitor GS-9450 accompanied by a lower expression of caspase-3 and -8 on peripheral T-cells. Furthermore, at baseline percentages of activated caspase-3, activated caspase-8 and CD95+ T-cells were higher in chronic $\mathrm{HCV}$-infected patients compared to healthy controls.

Keywords Hepatitis C virus - Apoptosis - Caspase-3 . Caspase-8 - CD95

\section{Introduction}

Persistence of the Hepatitis C Virus (HCV) in the liver leads to the development of liver fibrosis over the course of decades [1]. This process of liver fibrosis progression is a complex interplay between activated T-cells, activated 
stellate cells and apoptosis of injured hepatocytes [2]. Apoptosis or programmed cell death is a physiological phenomenon that occurs in most organs in the human body and is a key element in the host defense against viral pathogens [3]. The main signaling pathway to induce apoptosis in hepatic diseases and normal healthy livers is the death receptor pathway consisting of different receptors of the Tumor Necrosis Factor family being TNF-related apoptosis-inducing ligand (TRAIL), TNF-alpha and Fas (CD95/APO-1) [4]. Fas ligand (FasL) is expressed by natural killer cells and cytotoxic T lymphocytes (CTLs, i.e. CD8+ effector T-cells) and Fas-FasL interaction is the main effector mechanism of CTLs inducing apoptosis of virus infected hepatocytes [5, 6]. Recently, in a HCV genotype $1 \mathrm{~b}$ transgenic mouse model an increased rate of apoptosis of peripheral CD4+ and CD8+ T-cells was noted when compared to healthy control mice [7]. Furthermore, this was associated with an up-regulation of FasL on the hepatocytes suggesting that the hepatic microenvironment, with up-regulation of FasL, promotes increased T-cell apoptosis and thereby contributes to viral persistence.

Apoptosis is gradually being more recognized as an important factor in liver fibrosis development [8-10]. Caspases, proteolytic enzymes belonging to a family of intracellular cysteine proteases, play an important role in this apoptotic process. After interaction with the cell surface Fas-receptor, intra-cellular activation of death domains (FADD) result in proteolytic cleavage pro-caspase- 8 into its active form caspase-8 [11]. This process leads downstream to the cleavage of pro-caspase- 3 into its active form caspase-3, the central protease in the apoptosis pathway. The role of apoptosis in chronic HCV is currently not well understood. Liver biopsy studies in patients with chronic HCV have shown an increased presence of apoptotic hepatocytes [12, 13]. Moreover, the percentage of apoptotic hepatocytes, demonstrated immunohistochemically as caspase- 3 positive cells, has been shown to correlate with the amount of liver fibrosis [14, 15].

GS-9450 is an irreversible inhibitor of caspase-8, -9, and -1 and has demonstrated hepatoprotective activity in both fibrosis assays and apoptosis animal models (unpublished). Furthermore, a phase-1 trial dosing GS9450 for 14 days in healthy volunteers proved to be safe and well tolerated [16]. Recently, the results of a phase-2a study, evaluating the safety and tolerability of GS-9450 have been presented [17]. However, since both a baseline liver biopsy was not mandatory for entering the phase-2 study and in the previous phase-1 study, the effect of GS9450 on the T-cells was not evaluated, it was decided to analyze the effects of GS-9450 on peripheral T-cell apoptosis during GS-9450 therapy as a sub study during the phase-2a study.

\section{Patients and methods}

\section{Clinical study}

The GS-US-227-0102 was a phase 2a trial evaluating the safety and tolerability GS-9450, a potent irreversible inhibitor of caspase- $8,-9$, and -1 . This novel drug is currently developed by Gilead Inc. (Durham, NC, USA). Ascending doses of GS-9450 were evaluated in this randomized placebo-controlled study [17]. For the first cohort of $10 \mathrm{mg}$ GS-9450, 8 patients were included from the Netherlands, 6 receiving GS-9450 and 2 receiving placebo. Inclusion was based on the presence of a chronic HCV infection and ALT or AST $>1.5 \times$ the upper limit of normal (ULN; in our centre $35 \mathrm{U} / \mathrm{l}$ ). Furthermore, patients had to have previously failed conventional anti-HCV therapy, were unable to tolerate it, or had contraindications for treatment with (peg)interferon-alfa/ribavirin. Important exclusion criteria were decompensated liver disease or evidence of hepatocellular carcinoma (based on liver biopsy within the previous 2 years), coinfection with hepatitis B virus (HBV) or human immunodeficiency virus (HIV) and current or near future pregnancy. A laboratory sub study of this trial was designed for this first cohort, evaluating the effects of GS-9450 on peripheral T-cells.

\section{PBMC processing}

Peripheral blood (approximately $30 \mathrm{ml}$ ) was collected at baseline (i.e. day 0 of the study), at week 2 (i.e. day 14 of the study) and at week 7 (i.e. 5 weeks off-treatment followup). Within $24 \mathrm{~h}$, peripheral blood mononuclear cells (PBMC) were isolated using a Ficoll-Hypaque density gradient centrifugation. Cells were re-suspended in RPMI 1640 (Gibco Life Technologies, Breda, The Netherlands) to which $20 \%$ fetal calf serum and $1 \%$ penicillin and streptomycin were added (hereafter called medium). Except for the caspase-8 experiment, which were performed on frozen PBMC, all assays were performed on fresh PBMC. As controls, blood of 5 healthy individuals (Healthy Controls, HC) was requested from the local blood bank (screened and negative for hepatitis B, HIV and hepatitis C).

Selection of apoptosis markers on peripheral T-cells

In vitro analysis of the caspase-inhibitor GS-9450 showed inhibition of activated caspase- 8 . Since caspase- 3 (i.e. the main caspase protein in the apoptosis pathway) is a downstream caspase it was assumed that by inactivating caspase-8, the expression of caspase-3 would be reduced. Furthermore, CD95 of Fas is the main receptor initiating apoptosis in $\mathrm{HCV}$-infected patients and upstream of 
caspase- 8 . Therefore, CD95, caspase- 3 and -8 were chosen as markers for the measurement of apoptosis in peripheral T-cells. Although annexin-V/PI is a well-known assay to establish apoptosis, we choose to examine those markers that are directly involved in the working mechanism of GS9450.

\section{Apoptosis analysis by FACS}

PBMC in medium were washed and resuspended in PBA (phosphate buffered saline containing $0.16 \%$ BSA and $0.1 \%$ sodium-azide) to a concentration of 2 million PBMC/ $\mathrm{ml}$ and divided in aliquots of $200 \mu \mathrm{l}$. Cells were incubated for $15 \mathrm{~min}$ at $4^{\circ} \mathrm{C}$ with 2 different sets of antibodies: (i) against activated caspase-3 (FITC, BD Biosciences, San José, CA, USA) and (ii) against activated caspase-8 (FITC, Biovision, Mountain View, CA, USA) Added to both these two different sets were antibodies against CD3 (pacific Blue), CD4 (PECy7, BD), CD8 (APCCy7, eBioscience, San Diego, USA) and CD95 (PE, BD). Cells for caspaseexpression were washed and permeabilized with permalysis buffer (BD) and stained with antibodies for activated caspase- 3 or activated caspase- 8 for $15 \mathrm{~min}$ at $4^{\circ} \mathrm{C}$. After washing, cells were fixed with Cellfix (BD) and at least 200,000 cells were acquired by Fluorescence Activated Cell Sorting (FACS, LRSII, BD).

Using the FACSDiva software (BD), we constructed a CD4 PECy7 and CD8 APCCy7 scatter plot, gated CD3+ T-cells, in order to identify all $\mathrm{CD} 3+\mathrm{CD} 4+$ and $\mathrm{CD} 3+\mathrm{CD} 8+\mathrm{T}$-cells. Within these populations we gated on activated caspase- 3 and CD95 to obtain the percentage of caspase or $\mathrm{CD} 95$ expressing $\mathrm{CD} 3+\mathrm{CD} 4+$ or $\mathrm{CD} 3+$ CD8+ T-cells.

\section{Statistical analysis}

Continuous data are presented as median values [with interquartile range (IQR)] and analyzed non-parametrically using a Mann-Whitney $U$-test for baseline values and a Friedman test for longitudinal analysis. Categorical variables are given as numbers of cases (percentage). A $P$ value $\leq 0.05$ was considered as statistically significant and all tests used were two-sided. All data were analyzed using GraphPad Prism (version 5.0 for Windows, GraphPad Software, San Diego, USA).

\section{Results}

Eight patients were randomized to receive either $10 \mathrm{mg}$ GS-9450 $(n=6)$ or placebo $(n=2)$. Patient characteristics are given in Table 1 showing that the majority of patients were male $(75 \%)$ with a median age of 50 years.
As mandatory for inclusion, all patients had elevated ALTvalues with a median of $118 \mathrm{U} / \mathrm{l}$. Baseline viral loads varied from 1,500 to $1,350,000 \mathrm{IU} / \mathrm{ml}$ with a median of $409,000 \mathrm{IU} / \mathrm{ml}$. Since inclusion of all genotypes was allowed, 4 patients $(50 \%)$ were infected with genotype 1,2 (25\%) with genotype 4 and $2(25 \%)$ with genotype 3 . Treatment with either GS-9450 or placebo was generally well tolerated with fatigue, headache and nausea being the most reported side-effects.

The efficacy of $10 \mathrm{mg}$ of GS-9450 was studied in a 14-day dosing trial. Irrespective of the allocated treatment group, ALT-values declined in 7 of 8 study subjects during the first 14 days of the study (Fig. 1a). In patients receiving GS-9450, median ALT-values dropped from 118 to $64 \mathrm{U} / \mathrm{l}$ $(-46 \%)$ rising again to $140 \mathrm{U} / \mathrm{l}(+19 \%)$ at week 7 (i.e. 5 weeks of treatment follow-up) $(P=0.006$; Friedman test). In one of the patients receiving placebo ALT-values did not change during the treatment period. In the other patient, ALT-values decreased from $178 \mathrm{U} / \mathrm{l}$ at baseline to $78 \mathrm{U} / 1(-56 \%)$ at day 14 and further declined to $59 \mathrm{U} / 1$ $(-67 \%)$ at week 7 while rigorously changing his lifestyle (i.e. discontinuation of alcohol consumption and loosing $15 \mathrm{~kg}$ of body weight). During the 14-day trial HCV viral loads remained stable within $1 \mathrm{log}$ in all but one patient (Fig. 1b). This patient experienced a $2.61 \log _{10}$ increase in HCV-RNA during the 14 day treatment period which declined but did not return to baseline value during follow-up.

Baseline expression of caspase-3, caspase-8 and CD95 on peripheral T-cells

Since a mouse model has suggested an interaction between HCV-infected hepatocytes and T-cell apoptosis contributing to viral persistence and liver biopsies were not performed at baseline, we were interested in the effects of GS-9450 on peripheral T-cells in chronic HCV patients in this study. In order to be able to interpret the expression of activated caspase-3, activated caspase- 8 and CD95 by peripheral T-cells, we first analyzed these markers in 5 healthy controls (HC). A representative flow cytometry dot plot of a healthy control demonstrating both CD4+ and CD8+ populations as well as the expression of activated caspase-3 and CD95 on CD8+ T-cells is shown in Fig. 2a. Furthermore, expression of activated caspase- 3 and CD95 is shown on CD8+ T-cells of a patient (Fig. 2b). The median percentage of intra-cellular activated caspase-3 expression in $\mathrm{HC}$ was $0.4 \%$ (IQR $0.1-1.1$ ) for CD4+ T-cells and $0.1 \%$ (IQR 0-0.9) for CD8+ T-cells. Compared to these $\mathrm{HC}$, higher rates of activated caspase- 3 were detected in HCV-infected patients in CD4+ T-cells (median 9.7\% with IQR 6.2-25.5; $P=0.002$ ) and CD8+ T-cells (median 3.3\% with IQR 1.5-8.5; $P=0.01$ ) (Fig. 3a). Expression of activated caspase- 8 by CD8+ 
Table 1 Characteristics of the patients treated with either GS-9450 or placebo

\begin{tabular}{|c|c|c|c|c|c|c|c|}
\hline Patient & $\begin{array}{l}\text { Age } \\
\text { (years) }\end{array}$ & Sex & $\begin{array}{l}\text { HCV-RNA } \\
(\mathrm{IU} / \mathrm{ml})\end{array}$ & Genotype & $\begin{array}{l}\text { ALAT } \\
(\mathrm{U} / 1)\end{array}$ & Side-effects & Treatment \\
\hline 1001 & 49 & Male & 438,000 & $1 b$ & 121 & Dizziness and nausea & $10 \mathrm{mg}$ \\
\hline 1002 & 56 & Female & $1,200,000$ & $4 a / 4 c / 4 d$ & 109 & Fatigue, somnolence and feeling hot & $10 \mathrm{mg}$ \\
\hline 1003 & 43 & Male & 39,000 & $4 a / 4 c / 4 d$ & 178 & $\begin{array}{l}\text { Hyperhidrosis, affect lability, flank pain } \\
\text { and tooth infection }\end{array}$ & Placebo \\
\hline 1004 & 51 & Female & 894,000 & $3 a$ & 209 & $\begin{array}{l}\text { Headache, palpitations, dry skin, flank pain } \\
\text { and parosmia }\end{array}$ & $10 \mathrm{mg}$ \\
\hline 1005 & 40 & Male & 196,000 & $1 \mathrm{a}$ & 171 & $\begin{array}{l}\text { Vomiting, affect lability, nausea, headache, } \\
\text { sore throat, rhinitis and fatigue }\end{array}$ & $10 \mathrm{mg}$ \\
\hline 1006 & 40 & Male & 380,000 & $3 a$ & 115 & Affect lability & $10 \mathrm{mg}$ \\
\hline 1007 & 54 & Male & 1,500 & $1 \mathrm{a} / 1 \mathrm{~b}$ & 65 & Headache and gastro-enteritis & $10 \mathrm{mg}$ \\
\hline 1008 & 56 & Male & $1,350,000$ & $1 \mathrm{a}$ & 70 & Nausea, headache, fatigue and back pain & Placebo \\
\hline $\begin{array}{r}\text { Median } \\
(\mathrm{IQR})\end{array}$ & $\begin{array}{l}50 \\
\quad(51-56)\end{array}$ & NA & $\begin{array}{l}409,000 \\
\quad(78,250-1,124,000)\end{array}$ & NA & $\begin{array}{l}118 \\
(80-176)\end{array}$ & NA & NA \\
\hline
\end{tabular}

NA not applicable

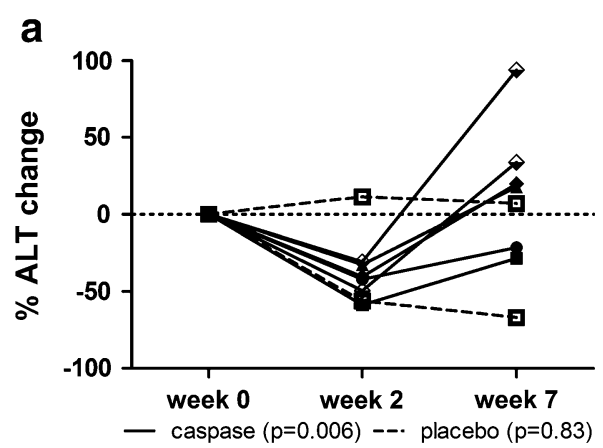

Fig. 1 Longitudinal analysis of ALT and HCV-RNA during therapy. Changes (\%) in plasma ALT (a) and change in HCV-RNA values (b) from baseline during the duration of the study. On the y-axis are the $\%$ change in ALT (U/l) and the $\Delta$ HCV-RNA $\left(\log _{10} \mathrm{IU} / \mathrm{ml}\right)$

T-cells was also significantly higher in chronic HCVpatients compared to HC [median 10.3 (IQR 6.5-22.8) and 3.90 (IQR 3.2-7.3); $P=0.02$ ] with a trend towards significance for the CD4+ T-cells [14.8 (IQR 7.5-41.0) and 6.7 (IQR 6.4-8.0); $P=0.07]$. Finally, surface expression of CD95 on CD4+ T-cells was higher in patients compared to $\mathrm{HC}$ [median $67.8 \%$ (IQR 54.8-78.9) and $46.4 \%$ (IQR 32.3-51.6); $P=0.02$ ] (Fig. 3b). However, this difference was not significant in CD8+ T-cells between patients [median 62.2\% (IQR 58.9-70.9)] and HC [median 36\% (IQR 27.6-60); $P=0.10]$.

Longitudinal analysis of caspase-3 and CD95 expression in peripheral T-cells

Next, we analyzed the expression of activated caspase-3, activated caspase- 8 and CD95 during the 14-day dosing period. Percentages of activated caspase-3+ CD4+ T-cells decreased in all patients (Fig. $4 \mathrm{a}$ ) during the study

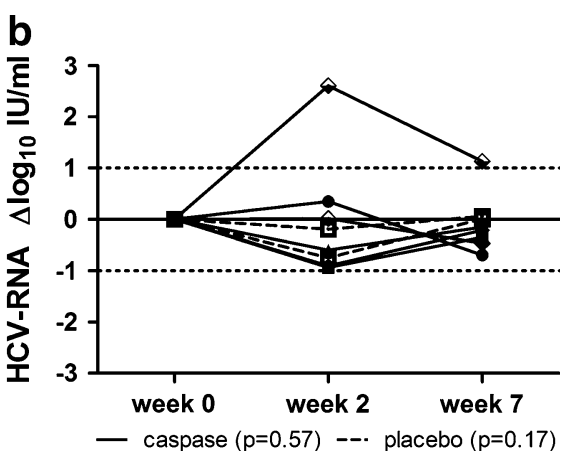

depicted. On the $x$-axis the weeks of the study are shown. Patients treated with the caspase-inhibitor GS-9450 are represented by the solid black lines and black dots and those receiving placebo are represented by the black dotted lines and open squares

period. In GS9450-treated patients the percentage of caspase-3+ CD4 T-cells went from a median of 16.2 to 6.3 and 9.9 at baseline, week 2 and 5 follow-up respectively $(P=0.05$; Friedman). This in contrast to the 2 placebo-treated patients showing no significant drop in caspase-3+ CD4 T-cells during the study period. At 5 weeks off-treatment follow-up, it was noted that in the majority of patients activated caspase- 3 expression returned to baseline values or even increased in the 2 patients receiving placebo during the dosing period. Activated caspase- 3 expression in CD8+ T-cells was more variable during the 14-days on treatment, decreasing in 4 of 8 patients $(50 \%)$ and increasing in the others (Fig. 4b). There was no significant difference in caspase$3+$ CD8+ T-cells changes in both GS9450-treated patients $(P=0.74)$ and placebo-treated patients $(P=$ 0.83 ). Five weeks after discontinuation, expression of activated caspase- 3 by CD8 + T-cells returned to baseline values in most patients. 
Fig. 2 Flow cytometry analysis of caspase-3 and CD95 expression. a Representation of a scatter plot defining a patient's CD4+ and CD8+ populations on the left. The middle and right plots represent expression of activated caspase- 3 and CD95 in a healthy control's CD8+ T-cells ( $x$-axis). b Flow cytometry dot plot showing a longitudinal expression of activated caspase-3 and CD95 in a chronic $\mathrm{HCV}$-infected patient treated with the caspaseinhibitor GS-9450. The upper row depicts the caspase- 3 expression while the lower row shows the CD95 expression (y-axis). From left to right, the study weeks 0,2 and 7 are depicted

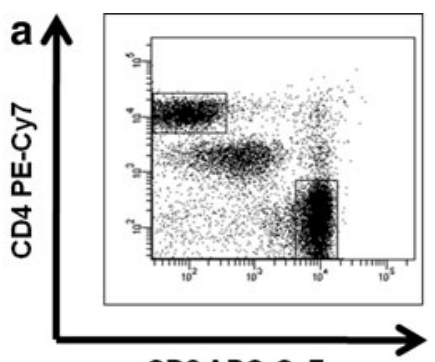

CD8 APC-Cy7

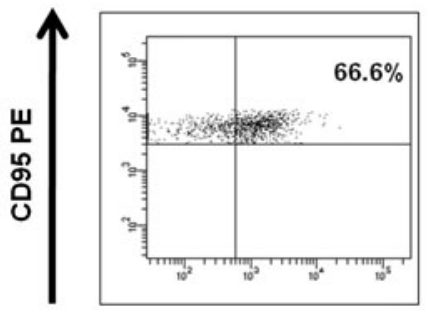

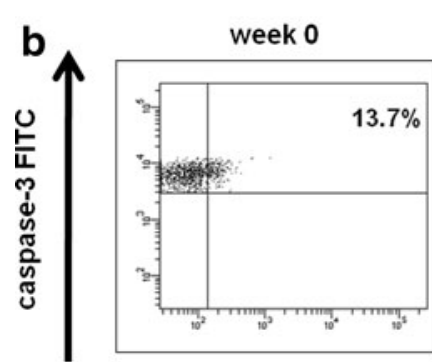
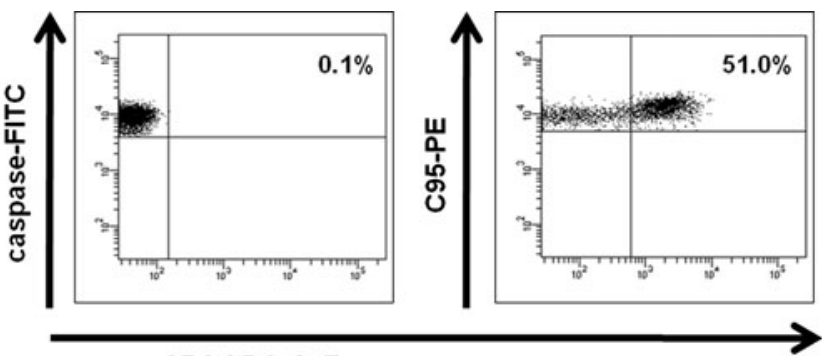

CD8 APC-Cy7
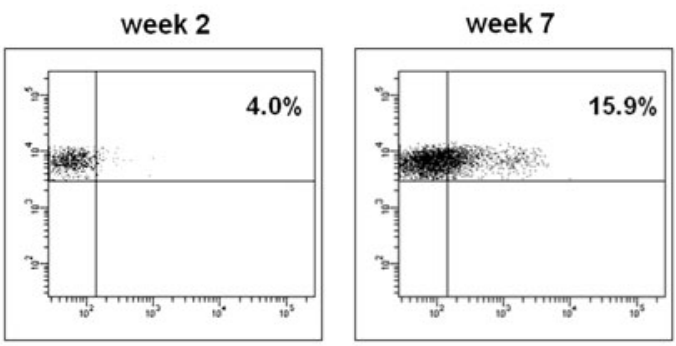

caspase-3
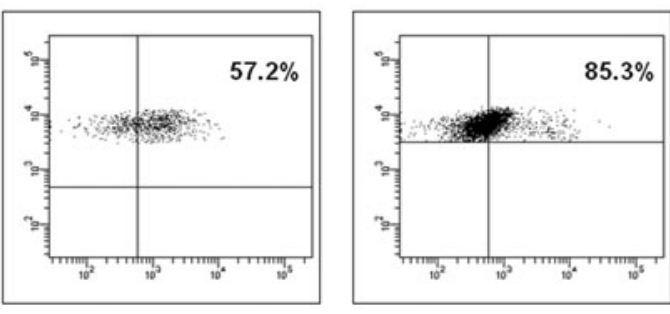

CD95

CD8 APC-Cy7
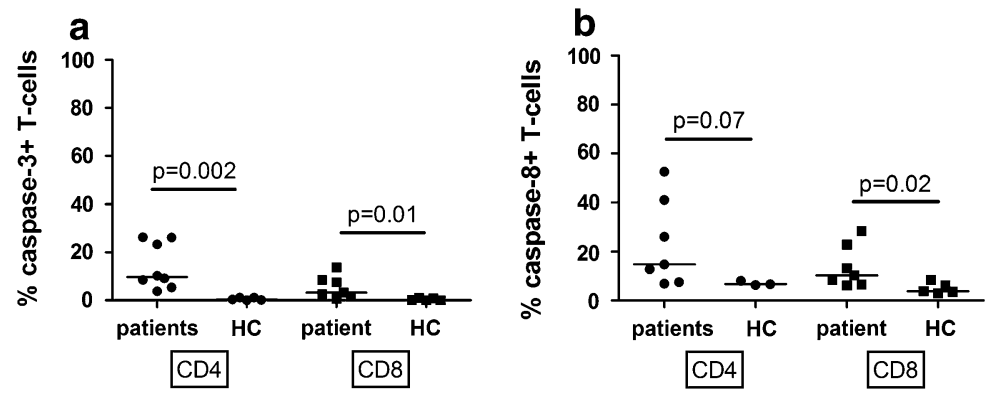

CD4

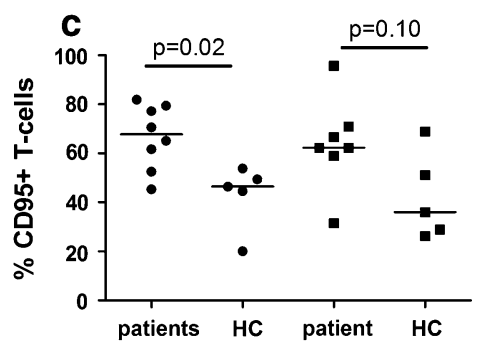

CD4

CD8
Fig. 3 Baseline expression of activated caspase-3 and CD95 in peripheral T-cells. Comparison of activated caspase- 3 (a), caspase- 8 (b) and CD95 (c) expression on peripheral T-cells between patients in the GS-9450 study at baseline and healthy controls (HC). On the $y$-axis the percentages of either activated caspase-3, caspase- 8 or

Since analysis of activated caspase- 8 expression was evaluated on frozen PBMC, we investigated the effects of freezing/thawing on activated caspase- 8 expression. Comparison of activated caspase- 8 expression between frozen and fresh PBMC in healthy controls did not show significant differences between the two methods $(P=0.64$; Wilcoxon signed rank test). Activated caspase- 8 expression in CD4+ T-cells decreased in all but one patient, returning
CD95 are depicted. The black dots represent CD4 T-cells and the black squares the CD8 T-cells. Of 1 patient FACS analysis of CD8+ T-cells failed resulting in 7 patients being evaluated. CD4+ T-cells of $2 \mathrm{HC}$ were unavailable for caspase- 8 analysis

to baseline in 3 patients or declining further in another 4 patients at week $7(P=0.74$ for GS9450 treated and $P=1.0$ for placebo treated patients; Friedman test) (Fig. 4c). Similarly, expression of activated caspase- 8 by CD8+ T-cells showed a decrease in 5 of 8 patients returning to baseline in 4 of them $(P=0.57$ for GS9450 treated and $P=0.50$ for placebo treated patients; Friedman test) (Fig. 4d). A mostly similar expression of 

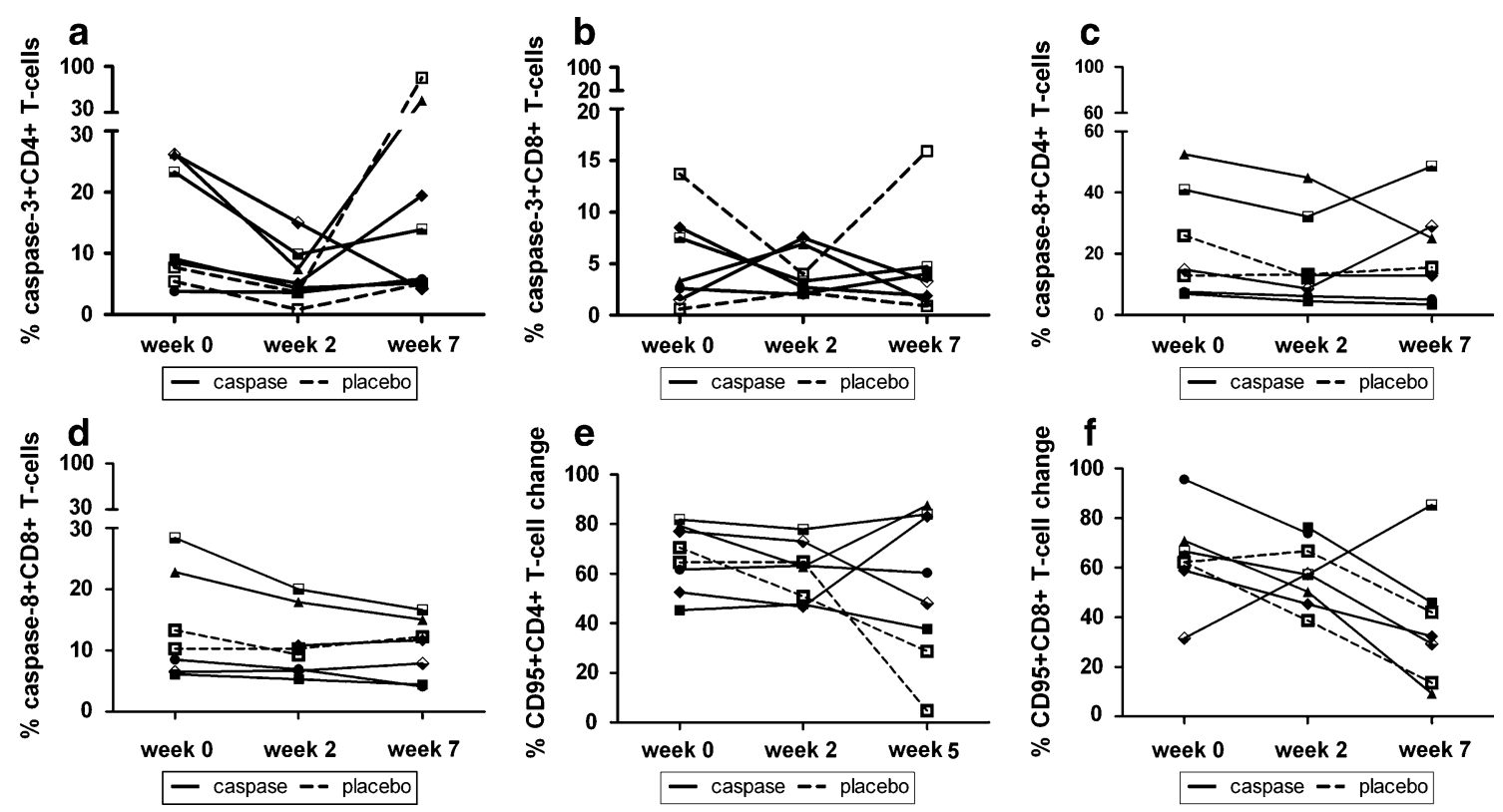

Fig. 4 Longitudinal analysis of activated caspase-3, caspase- 8 and CD95 expression Longitudinal analysis of CD4+ and CD8+ T-cells expressing activated caspase-3 (a, b), caspase-8 (c, d) and CD95 (e, f) during therapy. On the $y$-axis percentages of either activated caspase-3, caspase-8 or CD95 are shown and on the $x$-axis the weeks

activated caspase- 3 and activated caspase- 8 was noted in both placebo-treated and GS9450-treated patients demonstrating that inactivation of activated caspase- 8 lowers the downstream expression of activated caspase-3. This is also demonstrated by the significant correlation between the expression of activated caspase- 3 and activated caspase- 8 (Spearman $\mathrm{r}=0.40$ and $P=0.008$ ) when CD4+ and CD8+ T-cells at weeks 0,2 and 7 were analysed together.

Differences in expression of CD95 by CD4+ T-cells during the study were less pronounced and not significant with 5 patients showing minimal changes while 3 patients showed a decrease in CD95 expression (Fig. 4e). In CD8+ T-cells CD95 expression decreased in 5 of 8 patients from baseline to week 2 and even further at week 7 . A significant correlation between the expression of activated caspase-3 and CD95 was noted (Spearman $\mathrm{r}=0.34$ and $P=0.02$ ).

\section{Discussion}

In this study we evaluated the effects of the caspaseinhibitor GS-9450 on peripheral T-cells during a 14-day treatment period. Although treatment with GS-9450 resulted in lower ALT-values, it did not affect either the HCV viral load or the peripheral T-cells apoptosis rates. However, we demonstrate that at baseline, percentages of activated caspase- 3 , activated caspase- 8 and CD95 T-cells of the study are depicted. The black solid lines represent the patients receiving GS-9450 and the black dotted lines represent those taking placebo. One patient's CD8+ T-cells at baseline (see Fig. 3) and another patient's CD8+ T-cells at week 7 were not available for analysis

are higher in chronic $\mathrm{HCV}$-infected patients compared to healthy controls.

The effect of GS-9450 on lowering the ALT-value was strong (nearly 50\% reduction) suggesting a decrease in apoptotic hepatocytes and thus prevention of release of aminotransferase enzymes. In addition, cessation of alcohol consumption was a study requirement and might explain in part the ALT-decrease in these patients. This is supported by the observation that the ALT-values of one placebo-treated patient decreased during therapy and even further declined after placebo-discontinuation at the time ALT-values in GS-9450 treated patients increased again. A competitor caspase-inhibitor, of which development recently has been stopped, showed a similar decline in ALT-values (in a dose-depended matter) in chronic HCV patients in both a 14-day and a 12-week dosing trial $[18,19]$. In all these caspase-inhibitor studies an overshoot of aminotransferase activity occurred after discontinuation of the drug which might be caused by an abrupt release of blockade of apoptosis. This could be prevented by tapering instead of abrupt discontinuation and should be investigated in future studies.

In contrast to the decrease in ALT-values, treatment with GS-9450 did result only in a slight decrease in caspase- 8 expression on peripheral T-cells. In rats it was found that the concentration of GS-9450 was about 30-fold higher in the liver compared to peripheral blood. If this 
concentration difference is true for human, than this hepatoselective effects of GS-9450 could be one explanation for small effect on caspase-8 expression in peripheral T-cell. Another possible explanation for this small effect on caspase- 8 expression could be that the dose of $10 \mathrm{mg}$ GS9450 was too low to exert a larger effect on peripheral T-cell apoptosis while maximal concentrations were reached intra-hepatically. The relatively higher drop in activated caspase- 3 levels could be explained from the working mechanism of GS9450. By inactivating activated caspase- 8 , the percentage of downstream cascadic activated caspase- 3 expression is much more affected.

An interesting observation in this study was the significant differences in activated caspase-3, activated caspase8 and CD95 expression by peripheral T-cells between chronic HCV patients and healthy controls. This could not be explained by a difference in T-cell activation markers (HLA-DR/CD38) or T-cell phenotypes (CD27/CD45RO) since no difference between $\mathrm{HC}$ and $\mathrm{HCV}$-infected patients could be demonstrated for these T-cell features (data not shown). The reason for the higher rate of apoptosis in chronic $\mathrm{HCV}$ patients is currently unknown. It has been shown by Toubi et al. [20] that both spontaneous and dexamethasone-induced apoptosis was increased in chronic $\mathrm{HCV}$-infected patients compared to healthy individuals. They also showed that dexamethasone-induced apoptosis of peripheral T-cells was correlated with increased ALTvalues and decrease NF- $\kappa$ B levels. Furthermore, experimental HCV murine models have suggested that both HCV core and non-structural proteins enhance apoptosis of activated $\mathrm{CD} 4+$ and $\mathrm{CD} 8+\mathrm{T}$-cells via up-regulation of Fas-FasL interaction [7, 21]. This may suggest that HCV is capable of down-regulating specific immune responses by inducing $\mathrm{T}$-cell apoptosis and therefore contributing to persistence of a chronic HCV infection.

This study has several limitations. First, as staging of liver fibrosis was not part of the study, correlation between liver fibrosis and apoptosis-markers could not be performed. This would have been of interest given the earlier publications demonstrating a relation between intra-hepatic caspase expression and the degree of fibrosis [14]. When a correlation between the stage of liver fibrosis and peripheral T-cell apoptosis at baseline could be demonstrated, this might be a valuable marker for evaluation of liver fibrosis. However, no correlation was shown between ALT-values and either activated caspase-3, activated caspase-8 or CD95 expression (data not shown). Furthermore, the number of patients in this study was small possibly explaining the absence of significance in baseline CD95+CD8+ T-cells between HCV-infected patients and HC. Finally, the caspase- 8 analyses were performed on frozen T-cells. Freezing of cells is known to induce apoptosis in cells [3, 14]. However, the differences in activated caspase- 8 expression between fresh and frozen PBMC was limited (data not shown) and longitudinal changes in expression of activated caspase- 3 and activated caspase- 8 was similar. Therefore we think that the effects of freezing in this study is negligible. However, further studies of the role of activated caspase- 3 and activated caspase- 8 by peripheral T-cells is needed.

In conclusion, the caspase-inhibitor GS-9450 decreased ALT-values during a 14-day dosing period. Furthermore, the expression of activated caspase- 8 and mainly of activated caspase- 3 by peripheral T-cells decreased during the treatment period. Moreover, baseline expression of activated caspase- 3 , activated caspase- 8 and CD95 were found to be higher in patients with chronic HCV compared to healthy controls.

Conflict of interest Although this study was a laboratory sub study of the clinical trial GS-US-227-0102, the study was not sponsored by either company (Gilead and LG Life Sciences). K.R. Hirsch was employee of Gilead and J.G. Park is employee of LG Life Sciences. All other authors have no conflict of interest to report.

Open Access This article is distributed under the terms of the Creative Commons Attribution Noncommercial License which permits any noncommercial use, distribution, and reproduction in any medium, provided the original author(s) and source are credited.

\section{References}

1. Lauer GM, Walker BD (2001) Hepatitis C virus infection. N Engl J Med 345:41-52

2. Rockey DC, Bissell DM (2006) Noninvasive measures of liver fibrosis. Hepatology 43:S113-S120

3. Hotchkiss RS, Strasser A, McDunn JE, Swanson PE (2009) Cell death. N Engl J Med 361:1570-1583

4. Malhi H, Gores GJ (2008) Cellular and molecular mechanisms of liver injury. Gastroenterology 134:1641-1654

5. Schulze-Osthoff K, Ferrari D, Los M, Wesselborg S, Peter ME (1998) Apoptosis signaling by death receptors. Eur J Biochem 254:439-459

6. Hayashi N, Mita E (1999) Involvement of Fas system-mediated apoptosis in pathogenesis of viral hepatitis. J Viral Hepat 6:357-365

7. Iken K, Huang L, Bekele H, Schmidt EV, Koziel MJ (2006) Apoptosis of activated CD4+ and CD8 $+\mathrm{T}$ cells is enhanced by co-culture with hepatocytes expressing hepatitis $\mathrm{C}$ virus (HCV) structural proteins through FasL induction. Virology 346: 363-372

8. Fischer R, Baumert T, Blum HE (2007) Hepatitis C virus infection and apoptosis. World J Gastroenterol 13:4865-4872

9. Bantel H, Schulze-Osthoff K (2003) Apoptosis in hepatitis C virus infection. Cell Death Differ 10(Suppl 1):S48-S58

10. Guicciardi ME, Gores GJ (2005) Apoptosis: a mechanism of acute and chronic liver injury. Gut 54:1024-1033

11. Kountouras J, Zavos C, Chatzopoulos D (2003) Apoptosis in hepatitis C. J Viral Hepat 10:335-342

12. Calabrese F, Pontisso P, Pettenazzo E, Benvegnu L, Vario A, Chemello L, Alberti A, Valente M (2000) Liver cell apoptosis in chronic hepatitis $\mathrm{C}$ correlates with histological but not 
biochemical activity or serum HCV-RNA levels. Hepatology 31:1153-1159

13. Pianko S, Patella S, Ostapowicz G, Desmond P, Sievert W (2001) Fas-mediated hepatocyte apoptosis is increased by hepatitis C virus infection and alcohol consumption, and may be associated with hepatic fibrosis: mechanisms of liver cell injury in chronic hepatitis C virus infection. J Viral Hepat 8:406-413

14. Piekarska A, Kubiak R, Omulecka A, Szymczak W, Piekarski J (2007) Expression of tumour necrosis factor-related apoptosisinducing ligand and caspase- 3 in relation to grade of inflammation and stage of fibrosis in chronic hepatitis C. Histopathology 51:597-604

15. Bantel H, Lugering A, Poremba C, Lugering N, Held J, Domschke W, Schulze-Osthoff K (2001) Caspase activation correlates with the degree of inflammatory liver injury in chronic hepatitis $\mathrm{C}$ virus infection. Hepatology 34:758-767

16. Höppener F, Kim JA, Park MJ, Choi HJ (2010) Safety, tolerability, and pharmacokinetics of GS-9450 in healthy male and female volunteers. In: 44th Annual meeting of the European association for the study of the liver category $5 \mathrm{f}$

17. Manns MP, Lawitz E, Hoepelman IM, Choi HJ, Lee YJ, Cornpropst M, Liang W, King B, Hirsch KR, Oldach D, Rousseau FS (2010)
Short term safety, tolerability, pharmacokinetics and preliminary activity of GS-9450, a selective caspase inhibitor, in patients with chronic HCV infection. In: 45th Annual meeting of the European association for the study of the liver. Abstr. no. 15

18. Shiffman ML, Pockros P, McHutchison JG, Schiff ER, Morris M, Burgess G (2010) Clinical trial: the efficacy and safety of oral PF03491390, a pancaspase inhibitor-a randomized placebocontrolled study in patients with chronic hepatitis C. Aliment Pharmacol Ther 31:969-978

19. Pockros PJ, Schiff ER, Shiffman ML, McHutchison JG, Gish RG, Afdhal NH, Makhviladze M, Huyghe M, Hecht D, Oltersdorf T, Shapiro DA (2007) Oral IDN-6556, an antiapoptotic caspase inhibitor, may lower aminotransferase activity in patients with chronic hepatitis C. Hepatology 46:324-329

20. Toubi E, Kessel A, Goldstein L, Slobodin G, Sabo E, Shmuel Z, Zuckerman E (2001) Enhanced peripheral T-cell apoptosis in chronic hepatitis $\mathrm{C}$ virus infection: association with liver disease severity. J Hepatol 35:774-780

21. Soguero C, Joo M, Chianese-Bullock KA, Nguyen DT, Tung K, Hahn YS (2002) Hepatitis C virus core protein leads to immune suppression and liver damage in a transgenic murine model. J Virol 76:9345-9354 